\title{
Remarks on some starlike functions
}

\author{
Mamoru Nunokawa ${ }^{1}$ and Janusz Sokół $2^{*}$
}

\author{
${ }^{*}$ Correspondence: jsokol@prz.edu.pl \\ ${ }^{2}$ Department of Mathematics, \\ Rzeszów University of Technology, \\ Al. Powstańców Warszawy 12, \\ Rzeszów, 35-959, Poland \\ Full list of author information is \\ available at the end of the article
}

\begin{abstract}
Let $\mathcal{A}$ be the class of functions that are analytic in the unit disk $\mathbb{D}=\{z \in \mathbb{C}:|z|<1\}$ and normalized by $f(0)=f^{\prime}(0)-1=0$. In this work we investigate conditions under which $\left|z f^{\prime}(z) / f(z)-\delta\right|<\delta$. Next we also estimate $\left|\operatorname{Arg}\left\{f^{\prime}(z) / z\right\}\right|,\left|\operatorname{Arg}\left\{f(z) / z^{2}\right\}\right|$ and $\left|\operatorname{Arg}\left\{z f^{\prime}(z) / f(z)\right\}\right|$ for functions of the form $f(z)=z^{2}+a_{3} z^{3}+\cdots$ in the unit disc $|z|<1$, which satisfy $\left|f^{\prime \prime}(z)-2\right|<2$. Furthermore, some geometric consequences of these results are given.

MSC: Primary 30C45; secondary 30C80

Keywords: differential subordinations; Nunokawa's lemma; starlike functions of order alpha; convex functions of order alpha; strongly starlike functions of order alpha
\end{abstract}

\section{Introduction}

Let $\mathcal{A}$ be the class of functions that are analytic in the unit disk $\mathbb{D}=\{z \in \mathbb{C}:|z|<1\}$ and normalized by $f(0)=f^{\prime}(0)-1=0$. The subclasses of $\mathcal{A}$ consisting of functions that are univalent in $\mathbb{D}$, starlike with respect to the origin and convex will be denoted by $\mathcal{S}, \mathcal{S}^{*}$ and $\mathcal{C}$, respectively. The class $\mathcal{S}_{\alpha}^{*}$ of starlike functions of order $\alpha<1$ may be defined as

$$
\mathcal{S}_{\alpha}^{*}=\left\{f \in \mathcal{A}: \mathfrak{R e} \frac{z f^{\prime}(z)}{f(z)}>\alpha, z \in \mathcal{U}\right\} .
$$

The class $\mathcal{S}_{\alpha}^{*}$ and the class $\mathcal{C}_{\alpha}$ of convex functions of order $\alpha<1$

$$
\begin{aligned}
\mathcal{K}_{\alpha}: & =\left\{f \in \mathcal{A}: \mathfrak{R e}\left(1+\frac{z f^{\prime \prime}(z)}{f^{\prime}(z)}\right)>\alpha, z \in \mathcal{U}\right\} \\
& =\left\{f \in \mathcal{A}: z f^{\prime} \in \mathcal{S}_{\alpha}^{*}\right\}
\end{aligned}
$$

were introduced by Robertson in [1]. If $\alpha \in[0 ; 1)$, then a function in either of these sets is univalent. The convexity in one direction (it implies the univalence) of functions convex of negative order $-1 / 2$ was proved by Ozaki [2]. In [3] Pfaltzgraff et al. established that the constant $-1 / 2$ is, in a certain sense, the best possible. A lot of the other equivalent/sufficient conditions for univalence or for the starlikeness, or more, for the convexity in one direction, one can find in [3]. In this work we consider a similar problem, namely find $\alpha, \beta$ such that

$$
\mathfrak{R e}\left(1+\frac{z f^{\prime \prime}(z)}{f^{\prime}(z)}\right)<\alpha \Rightarrow\left|\frac{z f^{\prime}(z)}{f(z)}-\beta\right|<\beta .
$$

If $\beta \in(0,1]$, it implies also the starlikeness of $f$.

\section{基 Springer}

@2013Nunokawa and Sokół; licensee Springer. This is an Open Access article distributed under the terms of the Creative Commons Attribution License (http://creativecommons.org/licenses/by/2.0), which permits unrestricted use, distribution, and reproduction in any medium, provided the original work is properly cited. 


\section{Preliminaries}

The following lemma is a simple generalization of Nunokawa's lemma [4], which together with the lemma from [5] has a surprising number of important applications in the theory of univalent functions.

Lemma 2.1 [6] Let $p(z)=1+\sum_{n=m \geq 2}^{\infty} c_{n} z^{n}$ be an analytic function in $\mathbb{D}$. Suppose also that there exists a point $z_{0} \in \mathbb{D}$ such that

$$
\mathfrak{R e}\{p(z)\}>0 \text { for }|z|<\left|z_{0}\right|
$$

and

$$
\mathfrak{R e}\left\{p\left(z_{0}\right)\right\}=0 \text { and } p\left(z_{0}\right) \neq 0 .
$$

Then we have

$$
\frac{z_{0} p^{\prime}\left(z_{0}\right)}{p\left(z_{0}\right)}=i k
$$

where $k$ is a real number and

$$
k \geq \frac{m}{2}\left(a+\frac{1}{a}\right) \geq m \geq 2 \text { when } \operatorname{Arg}\left\{p\left(z_{0}\right)\right\}=\frac{\pi}{2}
$$

and

$$
k \leq-\frac{m}{2}\left(a+\frac{1}{a}\right) \leq-m \leq-2 \text { when } \operatorname{Arg}\left\{p\left(z_{0}\right)\right\}=-\frac{\pi}{2},
$$

where $\left|p\left(z_{0}\right)\right|=a$.

\section{Main results}

Theorem 3.1 Assume that $\delta \geq 3 / 4$ and $m$ is a positive integer such that $m>4 \delta-1$. If $f(z)=z+\sum_{n=m}^{\infty} a_{n} z^{n}$, and $z f^{\prime}(z) / f(z)$ are analytic in the unit disc $\mathbb{D}$ with $z f^{\prime}(z) \neq 2 \delta f(z)$, $f^{\prime}(z) \neq 0, z \in \mathbb{D}$ and

$$
\begin{aligned}
& \mathfrak{R e}\left\{1+\frac{z f^{\prime \prime}(z)}{f^{\prime}(z)}\right\} \\
& \quad< \begin{cases}2 \delta+(\delta-1 / 2)(m-1) & \text { for } \delta \in[3 / 4,1) \text { and } m \geq \delta /(1-\delta), m \in \mathbb{N}, \\
\frac{m-1}{2(2 \delta-1)} & \text { for } \delta \geq 1 \text { and } m>4 \delta-1, m \in \mathbb{N}, \\
\frac{m-1}{2(2 \delta-1)} & \text { for } \delta \in[3 / 4,1) \text { and } 4 \delta-1<m<\delta /(1-\delta), m \in \mathbb{N},\end{cases}
\end{aligned}
$$

then we have

$$
\left|\frac{z f^{\prime}(z)}{f(z)}-\delta\right|<\delta \quad \text { for }|z|<1 .
$$

Proof The function $z f^{\prime}(z) / f(z)$ is analytic in $\mathbb{D}$, thus we can define the function $p$ by

$$
\frac{z f^{\prime}(z)}{f(z)}-\delta=\delta \frac{p(z)+1-2 \delta}{p(z)-1+2 \delta} \quad \text { for }|z|<1,
$$

where $p(0)=1$, and $p(z)=1+p_{m-1} z^{m-1}+p_{m} z^{m}+\cdots, z \in \mathbb{D}$. 
Then it follows that

$$
1+\frac{z f^{\prime \prime}(z)}{f^{\prime}(z)}=\frac{2 \delta p(z)}{p(z)-1+2 \delta}+\frac{2 \delta-1}{p(z)-1+2 \delta} \frac{z p^{\prime}(z)}{p(z)} .
$$

If there exists a point $z_{0} \in \mathbb{D}$ such that

$$
\left|\frac{z f^{\prime}(z)}{f(z)}-\delta\right|<\delta \quad \text { for }|z|<\left|z_{0}\right|
$$

and

$$
\left|\frac{z_{0} f^{\prime}\left(z_{0}\right)}{f\left(z_{0}\right)}-\delta\right|=\delta
$$

then by (3.2)

$$
\mathfrak{R e}\{p(z)\}>0 \text { for }|z|<\left|z_{0}\right|
$$

and

$$
\mathfrak{R e}\left\{p\left(z_{0}\right)\right\}=0
$$

and $p\left(z_{0}\right) \neq 0$ by (3.3). Then applying Lemma 2.1 , we have

$$
\frac{z_{0} p^{\prime}\left(z_{0}\right)}{p\left(z_{0}\right)}=i k
$$

where

$$
k \geq \frac{(m-1)\left(a^{2}+1\right)}{2 a} \quad \text { when } \operatorname{Arg}\left\{p\left(z_{0}\right)\right\}=\frac{\pi}{2}
$$

and

$$
k \leq-\frac{(m-1)\left(a^{2}+1\right)}{2 a} \quad \text { when } \operatorname{Arg}\left\{p\left(z_{0}\right)\right\}=-\frac{\pi}{2}
$$

and where $p\left(z_{0}\right)= \pm i a$ and $0<a$. For the case $\operatorname{Arg}\left\{p\left(z_{0}\right)\right\}=\pi / 2, p\left(z_{0}\right)=i a$ and $0<a$ it follows from (3.3) that

$$
\begin{aligned}
\mathfrak{R e} & \left\{1+\frac{z_{0} f^{\prime \prime}\left(z_{0}\right)}{f^{\prime}\left(z_{0}\right)}\right\} \\
= & \mathfrak{R e} \frac{2 \delta i a}{i a-1+2 \delta}+\mathfrak{R e} \frac{(2 \delta-1) i k}{i a-1+2 \delta} \\
= & \frac{2 a^{2} \delta}{a^{2}+(2 \delta-1)^{2}}+\frac{(2 \delta-1) a k}{a^{2}+(2 \delta-1)^{2}} \\
= & \frac{2 a^{2} \delta+(2 \delta-1) a k}{a^{2}+(2 \delta-1)^{2}} .
\end{aligned}
$$


Therefore, we have from (3.4)

$$
\begin{aligned}
& \mathfrak{R e}\left\{1+\frac{z_{0} f^{\prime \prime}\left(z_{0}\right)}{f^{\prime}\left(z_{0}\right)}\right\} \\
& \geq \frac{2 a^{2} \delta+(2 \delta-1) a \frac{m-1}{2} \frac{a^{2}+1}{a}}{a^{2}+(2 \delta-1)^{2}} \\
& \quad=\frac{4 a^{2} \delta+(2 \delta-1)(m-1)\left(a^{2}+1\right)}{2\left(a^{2}+(2 \delta-1)^{2}\right)} \\
& \quad=2 \delta+(\delta-1 / 2)(m-1)+2 \delta(2 \delta-1) \frac{(m-1)(1-\delta)-(2 \delta-1)}{a^{2}+(2 \delta-1)^{2}} \text { for } a>0 .
\end{aligned}
$$

In the last expression, the numerator $(m-1)(1-\delta)-(2 \delta-1)$ is nonnegative if and only if $\delta \in[3 / 4,1)$ and $m \geq \delta /(1-\delta)$ but this expression tends to $0^{+}$when $a \rightarrow \infty$. Therefore, in this case we have

$$
\mathfrak{R e}\left\{1+\frac{z_{0} f^{\prime \prime}\left(z_{0}\right)}{f^{\prime}\left(z_{0}\right)}\right\} \geq 2 \delta+(\delta-1 / 2)(m-1) \quad \text { for } \delta \in[3 / 4,1) \text { and } m>\delta /(1-\delta) .
$$

Furthermore, the numerator $(m-1)(1-\delta)-(2 \delta-1)$ is negative if and only if $\delta \geq 1$ and $m \in \mathbb{N}$ or $\delta \in[3 / 4,1)$ and $m<\delta /(1-\delta)$. In this case the quotient decreases when $a \rightarrow 0^{+}$. Therefore, in this case we have

$$
\begin{aligned}
& \mathfrak{R e}\left\{1+\frac{z_{0} f^{\prime \prime}\left(z_{0}\right)}{f^{\prime}\left(z_{0}\right)}\right\} \\
& \geq 2 \delta+(\delta-1 / 2)(m-1)+\frac{2 \delta\{(m-1)(1-\delta)-(2 \delta-1)\}}{2 \delta-1} \\
& \quad=\frac{m-1}{2(2 \delta-1)} .
\end{aligned}
$$

We have assumed that $m>4 \delta-1$ to have the right-hand side in (3.1) greater to 1 . So in this case we have

$$
4 \delta-1<m<\frac{\delta}{1-\delta} \quad \text { for } \delta \in[3 / 4,1) .
$$

Therefore, we can write (3.6) in the form

$$
\begin{aligned}
& \mathfrak{R e}\left\{1+\frac{z_{0} f^{\prime \prime}\left(z_{0}\right)}{f^{\prime}\left(z_{0}\right)}\right\} \\
& \quad \geq \frac{m-1}{2(2 \delta-1)} \begin{cases}\text { either for } & \delta \geq 1 \text { and } m>4 \delta-1, m \in \mathbb{N}, \\
\text { or for } & \delta \in[3 / 4,1) \text { and } 4 \delta-1<m<\delta /(1-\delta) .\end{cases}
\end{aligned}
$$

Inequalities (3.5) and (3.8) contradict the hypothesis of Theorem 3.1, and therefore we have

$$
\mathfrak{R e}\{p(z)\}>0 \quad \text { for }|z|<1
$$

Furthermore, from (3.2) and (3.9) we obtain

$$
\left|\frac{z f^{\prime}(z)}{f(z)}-\delta\right|=\left|\delta \frac{p(z)+1-2 \delta}{p(z)-1+2 \delta}\right|<\delta \quad \text { for }|z|<1 .
$$


For the case $\operatorname{Arg}\left\{p\left(z_{0}\right)\right\}=-\pi / 2, p\left(z_{0}\right)=-i a$ and $0<a$, applying the same method as above, we also have (3.9). Therefore, we get (3.10), which completes the proof of Theorem 3.1.

Substituting $\delta=1$ in Theorem 3.1 leads to the following corollary.

Corollary 3.2 If $f(z)=z+\sum_{n=m}^{\infty} a_{n} z^{n}$ is analytic in the unit disc $\mathbb{D}$ and

$$
\mathfrak{R e}\left\{1+\frac{z f^{\prime \prime}(z)}{f^{\prime}(z)}\right\}<\frac{m-1}{2},
$$

then we have

$$
\left|\frac{z f^{\prime}(z)}{f(z)}-1\right|<1 \quad \text { for }|z|<1
$$

Substituting $\delta=3 / 4, m=3$ in Theorem 3.1 gives the following corollary.

Corollary 3.3 If $f(z)=z+\sum_{n=3}^{\infty} a_{n} z^{n}$ is analytic in the unit disc $\mathbb{D}$ and

$$
\mathfrak{R e}\left\{1+\frac{z f^{\prime \prime}(z)}{f^{\prime}(z)}\right\}<\frac{13}{8},
$$

then we have

$$
\left|\frac{z f^{\prime}(z)}{f(z)}-\frac{3}{4}\right|<\frac{3}{4} \quad \text { for }|z|<1 .
$$

Substituting $\delta=4 / 5, m=3$ in Theorem 3.1 gives the following corollary.

Corollary 3.4 Iff $(z)=z+\sum_{n=3}^{\infty} a_{n} z^{n}$ is analytic in the unit disc $\mathbb{D}$ and

$$
\mathfrak{R e}\left\{1+\frac{z f^{\prime \prime}(z)}{f^{\prime}(z)}\right\}<\frac{5}{2}
$$

then we have

$$
\left|\frac{z f^{\prime}(z)}{f(z)}-\frac{4}{5}\right|<\frac{4}{5} \quad \text { for }|z|<1
$$

As a supplement to the above results recall here the known result $[7, \mathrm{p} .61]$ that if $f(z)=$ $z+\sum_{n=2}^{\infty} a_{n} z^{n}$ is analytic in the unit disc $\mathbb{D}$ and

$$
\mathfrak{R e}\left\{1+\frac{z f^{\prime \prime}(z)}{f^{\prime}(z)}\right\} \prec R_{1,1}(z)=\frac{1+z}{1-z}+\frac{2 z}{1-z^{2}},
$$

then

$$
\mathfrak{R e} \frac{z f^{\prime}(z)}{f(z)}>0 \quad \text { for }|z|<1 .
$$

Note that the open door function $R_{1,1}(z)$ maps $\mathbb{D}$ onto the complex plane with slits along the half-lines $\mathfrak{R e}\{w\}=0$, and $|\mathfrak{I m}\{w\}| \geq \sqrt{3}$. Next we give the bounds for $\left|\operatorname{Arg}\left\{z f^{\prime}(z) / f(z)\right\}\right|$. 
Theorem 3.5 Let $f(z)=z^{2}+\sum_{n=3}^{\infty} a_{n} z^{n}$ be analytic in the unit disc $\mathbb{D}$. If

$$
\left|f^{\prime \prime}(z)-2\right|<2 \text { for }|z|<1
$$

then

$$
\left|\frac{f^{\prime}(z)}{z}-2\right|<1 \quad \text { for }|z|<1 .
$$

Proof By the Schwarz lemma we have

$$
\left|f^{\prime \prime}\left(t e^{i \varphi}\right)-2\right| \leq 2 t, \quad t \in[0,1)
$$

Let $z=r e^{i \varphi}, r \in[0,1)$, and let $\varphi$ be fixed. Using this we obtain

$$
\begin{aligned}
\left|\frac{f^{\prime}(z)}{z}-2\right| & =\frac{\left|f^{\prime}(z)-2 z\right|}{|z|} \\
& =\frac{\left|\int_{0}^{z}\left(f^{\prime \prime}(u)-2\right) \mathrm{d} u\right|}{|z|} \\
& =\frac{\left|\int_{0}^{r}\left(f^{\prime \prime}\left(t e^{i \varphi}\right)-2\right) \mathrm{d}\left(t e^{i \varphi}\right)\right|}{\left|r e^{i \varphi}\right|} \\
& =\frac{\left|\int_{0}^{r} e^{i \varphi}\left(f^{\prime \prime}\left(t e^{i \varphi}\right)-2\right) \mathrm{d} t\right|}{\left|r e^{i \varphi}\right|} \\
& \leq \frac{\int_{0}^{r}\left|e^{i \varphi}\left(f^{\prime \prime}\left(t e^{i \varphi}\right)-2\right)\right| \mathrm{d} t}{\left|r e^{i \varphi}\right|} \\
& \leq \frac{\int_{0}^{r} 2 t \mathrm{~d} t}{r} \\
& =\frac{r^{2}}{r}=r<1 .
\end{aligned}
$$

Therefore, we obtain (3.12).

For the function $f(z)=z^{3} / 3+z^{2}$, condition (3.11) is satisfied while (3.12) becomes $|z|<1$ in the unit disc, which shows that the constant 1 in (3.12) cannot be replaced by a smaller one. A simple geometric observation yields the following corollary.

Corollary 3.6 Let $f(z)=z^{2}+\sum_{n=3}^{\infty} a_{n} z^{n}$ be analytic in the unit disc $\mathbb{D}$. If

$$
\left|f^{\prime \prime}(z)-2\right|<2 \text { for }|z|<1
$$

then

$$
\left|\operatorname{Arg}\left\{\frac{f^{\prime}(z)}{z}\right\}\right|<\frac{\pi}{6} \quad \text { for }|z|<1
$$

Using the same method as in the proof of Theorem 3.5, we can obtain the following result. 
Theorem 3.7 Let $f(z)=z^{2}+\sum_{n=3}^{\infty} a_{n} z^{n}$ be analytic in the unit disc $\mathbb{D}$. If

$$
\left|f^{\prime \prime}(z)-2\right|<2 \quad \text { for }|z|<1 \text {, }
$$

then

$$
\left|\frac{f(z)}{z^{2}}-1\right|<\frac{1}{3} \quad \text { for }|z|<1 .
$$

For the function $f(z)=z^{3} / 3+z^{2}$, condition (3.15) is satisfied while (3.16) becomes $|z / 3|<$ $1 / 3$ in the unit disc, which shows that the constant $1 / 3$ in (3.16) cannot be replaced by a smaller one. A simple geometric observation yields the following corollary.

Corollary 3.8 Let $f(z)=z^{2}+\sum_{n=3}^{\infty} a_{n} z^{n}$ be analytic in the unit disc $\mathbb{D}$. If

$$
\left|f^{\prime \prime}(z)-2\right|<2 \text { for }|z|<1
$$

then

$$
\left|\operatorname{Arg}\left\{\frac{f(z)}{z^{2}}\right\}\right|<\sin ^{-1} \frac{1}{3} \quad \text { for }|z|<1 .
$$

Using Corollaries 3.6 and 3.8 together, we obtain the next one.

Corollary 3.9 Let $f(z)=z^{2}+\sum_{n=3}^{\infty} a_{n} z^{n}$ be analytic in the unit disc $\mathbb{D}$. If

$$
\left|f^{\prime \prime}(z)-2\right|<2 \text { for }|z|<1 \text {, }
$$

then

$$
\left|\operatorname{Arg}\left\{\frac{z f^{\prime}(z)}{f(z)}\right\}\right|<\frac{\pi}{6}+\sin ^{-1} \frac{1}{3} \approx 0.8634 \text { for }|z|<1 .
$$

Proof From (3.12) and from (3.16), we have

$$
\begin{aligned}
\left|\operatorname{Arg}\left\{\frac{z f^{\prime}(z)}{f(z)}\right\}\right| & =\left|\operatorname{Arg}\left\{\frac{f^{\prime}(z)}{z} \frac{z^{2}}{f(z)}\right\}\right| \\
& \leq\left|\operatorname{Arg}\left\{\frac{f^{\prime}(z)}{z}\right\}\right|+\left|\operatorname{Arg}\left\{\frac{f(z)}{z^{2}}\right\}\right| \\
& <\frac{\pi}{6}+\sin ^{-1} \frac{1}{3} \\
& \approx 0.8634 .
\end{aligned}
$$

Recall the class $\mathcal{S S}^{*}(\beta)$ of strongly starlike functions of order $\beta, 0<\beta \leq 1$,

$$
\mathcal{S S}^{*}(\beta):=\left\{f \in \mathcal{A}:\left|\operatorname{Arg} \frac{z f^{\prime}(z)}{f(z)}\right|<\frac{\beta \pi}{2}, z \in \mathbb{U}\right\},
$$

which was introduced in [8] and [9]. Therefore, Corollary 3.9 says that if $f$ satisfies the assumptions, then it is 2 -valently strongly starlike of order at least 0.8634 . 


\section{Competing interests}

The authors declare that they have no competing interests.

\section{Authors' contributions}

All authors jointly worked on the results, and they read and approved the final manuscript.

\section{Author details}

${ }^{1}$ University of Gunma, Hoshikuki-cho 798-8, Chuou-Ward, Chiba, 260-0808, Japan. ²Department of Mathematics, Rzeszów University of Technology, Al. Powstańców Warszawy 12, Rzeszów, 35-959, Poland.

\section{Received: 12 November 2013 Accepted: 5 December 2013 Published: 30 Dec 2013}

\section{References}

1. Robertson, MS: On the theory of univalent functions. Ann. Math. 37, 374-408 (1936)

2. Ozaki, S: On the theory of multivalent functions. Sci. Rep. Tokyo Bunrika Daigaku 4, 45-86 (1941)

3. Pfaltzgraff, JA, Reade, MO, Umezawa, T: Sufficient conditions for univalence. Ann. Fac. Sci. Kinshasa Zaïre Sect. Math.-Phys. 2, 94-100 (1976)

4. Nunokawa, M: On properties of non-Carathéodory functions. Proc. Jpn. Acad. Ser. A 68(6), 152-153 (1992)

5. Nunokawa, M: On the order of strongly starlikeness of strongly convex functions. Proc. Jpn. Acad. Ser. A 69(7), 234-237 (1993)

6. Nunokawa, M, Sokół, J: New conditions for starlikeness and strongly starlikeness of order alpha (submitted)

7. Miller, SS, Mocanu, PT: Differential Subordinations: Theory and Applications. Series of Monographs and Textbooks in Pure and Applied Mathematics, vol. 225. Dekker, New York (2000)

8. Stankiewicz, J: Quelques problèmes extrêmaux dans les classes des fonctions $\alpha$-angulairement étoilées. Ann. Univ. Mariae Curie-Skłodowska, Sect. A 20, 59-75 (1966)

9. Brannan, DA, Kirwan, WE: On some classes of bounded univalent functions. J. Lond. Math. Soc. 1(2), 431-443 (1969)

10.1186/1029-242X-2013-593

Cite this article as: Nunokawa and Sokół: Remarks on some starlike functions. Journal of Inequalities and Applications 2013, 2013:593

\section{Submit your manuscript to a SpringerOpen ${ }^{\circ}$ journal and benefit from:}

- Convenient online submission

- Rigorous peer review

Immediate publication on acceptance

- Open access: articles freely available online

- High visibility within the field

- Retaining the copyright to your article 